\title{
MUSEO A CIELO ABIERTO EN SAN MIGUEL COMO EXPERIENCIA DE PAISAJE MUSEALIZADO
} MUSEO A CIELO ABIERTO EN SAN MIGUEL LIKE
AN EXPERIENCE OF MUSEALIZED LANDSCAPE

\section{Daniela Derosas Contreras \\ Universidad Autónoma de Madrid}

\author{
Alfonso García de la Vega \\ Universidad Autónoma de Madrid
}

Resumen El autodenominado Museo a Cielo Abierto en San Miguel es el resultado del esfuerzo de los vecinos de la comuna de San Miguel (en Santiago de Chile), para embellecer el barrio. Si bien, la iniciativa surge con la intención de mejorar el espacio urbano a propósito del bicentenario de Chile, este espacio adoptó ciertos elementos de los museos tradicionales a través de la pintura mural en las medianeras de las viviendas.

A partir del desglose de la definición de museos del ICOM, en su revisión del año 2017, se han creado tres categorías para el análisis cualitativo de las actuaciones del Museo a Cielo Abierto en San Miguel: estar en posesión de un patrimonio material o inmaterial, brindar un servicio a la sociedad y políticas de restauración y conservación de sus piezas. Finalmente, se concluye que efectivamente este espacio constituiría un paisaje urbano musealizado.

Palabras clave Museo a Cielo Abierto en San Miguel, paisaje urbano musealizado, museo al aire libre.

Abstract The self-named Open Sky Museum in San Miguel is the result of the effort of the neighbours of the commune of San Miguel (in Santiago de Chile), to beautify the neighbourhood. Although the initiative arose with the intention of improving the urban space due to the bicentennial of Chile, this space adopted certain elements of the traditional museums through the mural painting in the dividing walls of the houses.

Following the breakdown of the ICOM definition of museums, in its 2017 revision, three categories have been created for the qualitative analysis of the actions of the Open Sky Museum in San Miguel: to be in possession of a material or immaterial heritage, to offer a service to society, and policies of restoration and conservation of its pieces. Finally, it is concluded that this space would effectively constitute a musealized urban landscape.

Keywords Open-air Museum in San Miguel, Musealized Urban Landscape, Open-Air Museum. 


\section{Introducción}

El Museo a Cielo Abierto en San Miguel nace como una propuesta de los vecinos de la comuna de San Miguel en Santiago de Chile. Esta iniciativa surge a partir de la celebración del Bicentenario de Chile en 2010, con el objetivo de mejorar el barrio a través de la incorporación de un nuevo patrimonio artístico, basado sobre algunos elementos significativos de la cultura chilena. Tras casi una década de funcionamiento, el proyecto germinal de los vecinos para la renovación de la comuna, se convierte en el autodenominado «Museo a Cielo Abierto», y puede ser comprendido bajo la lógica de paisaje musealizado.

El paisaje musealizado supone una transformación en el medio urbano, que adhiere ciertas características propias de los museos al uso. Sin embargo, la principal diferencia entre los paisajes musealizados y los museos tradicionales consistirá en la ubicación, ya que son espacios abiertos y habitados. Esta transformación estética del paisaje incide en el imaginario colectivo de residentes y observadores, modificando la percepción sobre el medio. Mediante el análisis de las principales actuaciones y características del Museo a Cielo Abierto en San Miguel se pretende justificar si este espacio corresponde a un paisaje musealizado.

\section{Marco teórico}

\subsection{Surgimiento de los museos al aire libre}

Desde sus orígenes, los museos se han presentado de forma persistente como guardianes del patrimonio de la humanidad. No obstante, el patrimonio resulta ser un término flexible y que ha ido adquiriendo matices. Así, en las últimas décadas, los museos han incorporado diversos elementos patrimoniales, que han incurrido en una diversificación de matices emocionales y significados conceptuales.
Como consecuencia de esta heterogeneidad, surgen los llamados museos a cielo abierto, correspondiente al término anglosajón open air museum. Conviene aclarar que tanto «museo a cielo abierto» como «museos al aire libre» se utilizan indistintamente para hacer referencia a este tipo de instituciones inscritas directamente en el paisaje.

En el siglo XIX y en el norte de Europa, estos museos se denominaron museos etnográficos o ecomuseos, y tenían como propósito principal reflejar las formas de vida popular y tradicional (Fernández de Paz, 1997). El Skansen fue el primer ecomuseo, y sentó las bases que regirán a este tipo de instituciones hasta principios del siglo $\mathrm{xx}$. Los ecomuseos reproducían los modos de vida tradicionales mediante actividades in situ (Tomàs, 2012). Aquí también se incluían los museos del régimen nacionalsocialista alemán conocidos como Heimatmuseum, que buscaban legitimar el nazismo por medio de soportes científicoprácticos (Crus-Ramirez, 1985).

Posteriormente, dentro de la tipología de museos al aire libre se incorpora a los yacimientos arqueológicos que, ante la imposibilidad de desvincular ubicación y piezas, se transforman en museos a cielo abierto (Vilas, 1999). En Europa, este tipo de museos está regido por la International Organisation of Archaeological Open-Air Museums and Experimental Archaeology (en sus siglas EXARC), organismo dependiente del International Council of Museums (en adelante IсOм).

En Latinoamérica, el desarrollo de los museos data de finales del siglo XIX y principios del $\mathrm{xx}, \mathrm{y}$ se vio condicionado por las transformaciones políticas de países que necesitaban reforzar su identidad nacional mediante el patrimonio material y cultural (Instituto Brasileiro de $\mathrm{Mu}$ seus, 2014). Este esquema fue cuestionado y discutido en la Mesa Redonda de Santiago de Chile en mayo del año 1972 (Lopes \& Murrie1lo, 2005). Dicha reunión sentó las bases para 
la creación de una nueva museografía latinoamericana centrada fundamentalmente en el discurso social y no en el estatal (Azócar, 2007). Como resultado nacen los museos vecinales o comunitarios, que se caracterizan por surgir de la iniciativa de la comunidad para contribuir en la solución de algunas de sus necesidades (De Carli, 2004).

\subsection{Definición de museos}

La diversidad de instituciones que existen en la actualidad, requiere que se busque una definición apropiada que sirva para comprender el amplio abanico de museos en su complejidad. No obstante, bastará con una rápida revisión de la bibliografía para constatar que, al menos en un sentido global, la más completa y actualizada es la del ICOM. Otras definiciones se centran en tipologías de museo específicas, dificultando la existencia de un consenso al respecto de la institución como tal.

En este aspecto, Carbonell (2005) expone que un museo debe definirse en base a sus funciones, ya que estas le permitirán integrarse de manera eficiente y renovada en la sociedad actual. Dentro de estas funciones, el autor destaca como primordial la generación de conocimiento, es decir, una labor educativa y de investigación. Esta función debe complementarse con la difusión de ese conocimiento, permitiendo el acercamiento y comprensión por parte de un público no especializado.

El ICOM, trata el tema de manera global, y actualiza su definición periódicamente. En su revisión del año 2017, señala que los museos son:

...una institución sin fines lucrativos, permanente, al servicio de la sociedad y de su desarrollo, abierta al público, que adquiere, conserva, investiga, comunica y expone el patrimonio material e inmaterial de la humanidad y su medio ambiente con fines de educación, estudio y recreo.
Según los estatutos del ICOM, no es necesario que una entidad esté afiliada al Consejo para ser considerada un museo, pero sí que se cumplan los requisitos expuestos en su definición. Sin embargo, la mencionada acepción resulta genérica en cuanto al significado de los términos que utiliza. La escasa claridad al respecto propicia una creciente oferta de instituciones que se autodenominan «museo», pero que no alcanzan a cumplir con las condiciones propuestas.

\subsection{Musealización del paisaje urbano}

Desvallées y Mairesse (2010) definen que la musealización «designa de una manera general la transformación de un lugar viviente en una especie de museo, ya sea centro de actividades humanas o sitio natural». Bajo esta perspectiva, la incorporación de nuevos elementos patrimoniales a partir del arte contemporáneo en el paisaje urbano de manera espontánea, sumada a la introducción de actuaciones museográficas, originan la transformación del paisaje en museo (García de la Vega y Derosas Contreras, 2017).

Según Lorente (2009), la intervención artística en el espacio público es un factor clave para el surgimiento de un barrio artístico. Por tanto, en el proceso de musealización, un espacio cotidiano se convierte en un paisaje único, con el resultado de generar un cambio en la identidad y dinámica de estos.

Así, la principal diferencia entre museos al aire libre y paisajes musealizados consiste en el origen museográfico; los primeros poseen un discurso museográfico preestablecido, en tanto que, los segundos, surgen desde el acuerdo espontáneo de los propios habitantes de ese espacio. En consecuencia, en el museo a cielo abierto las piezas preceden al paisaje y, por el contrario, en el paisaje musealizado el escenario natural o antropizado precede a la obra, integrándose armónicamente. 
Un ejemplo de esto se refleja en la experiencia del Museo Inacabado de Arte Urbano (en sus siglas MIAU), localizado en Fanzara (Castellón, España). A través de distintas actuaciones se manifiesta una intención artística que trasciende a lo contemplativo, revelando, además un propósito educativo y divulgativo. Los murales disponen de códigos QR que, tras su lectura, arrojan información sobre los artistas y las obras (Derosas Contreras, 2017). También dispone de talleres sobre arte urbano y graffiti para grupos escolares de España y Francia (MIAU Fanzara, s.f.).

El espacio urbano, como museo, conlleva un cambio en la percepción del paisaje por quienes lo observan y habitan. Así sucede en Beco da Codorna (Goiânia, Brasil), un antiguo parking que se había convertido en el epicentro de acciones ilegales y, que, gracias a un proyecto universitario, es intervenido por artistas pertenecientes al colectivo Grafima Graffiti e Design (Rodrigues, 2015). En la actualidad, Beco da Cordona se autodefine como un museo a cielo abierto y ha propiciado a este espacio una nueva identidad. Si bien, su discurso museográfico aún no es del todo sólido, ejecutan periódicamente actividades, incluido un festival anual de arte urbano, que sirve para la difusión del lugar.

2.4. Transformación del paisaje a través del arte urbano

La transformación del paisaje urbano mediante el arte es un tema que se remonta a la Belle Époque parisina. Como consecuencia del desarrollo de las artes plásticas, surge una tendencia a la renovación urbana que revalorizó algunos distritos que fueron posteriormente identificados como barrios artísticos, como por ejemplo Montmartre (Lorente, 2009).
Posteriormente, durante el siglo $\mathrm{xx}$, surgen dos movimientos que incorporan el arte contemporáneo in situ en el paisaje: el Land Art y el Arte Urbano. Ambas corrientes incurren en la transformación del paisaje mediante la realización de piezas artísticas indisociables del contexto donde se han realizado.

El Land Art surge como respuesta a los museos y galerías en la década de 1960, pues eran considerados espacios insuficientes para contener las nuevas tendencias artísticas ( $\mathrm{Ra}$ quejo, 2008). Los artistas comienzan a realizar piezas a gran escala, fuera de las instituciones, in situ en el medio natural (Ruhrberg et al., 2012). Esta experiencia abrió la posibilidad de invertir los roles, y trasladar el museo.

El Arte Urbano, también conocido como Street Art, es un movimiento que surge en Estados Unidos en la década de 1970, y que consiste en utilizar el contexto urbano como lienzo (Danysz, 2016). En un principio, este movimiento se conocía como graffiti, término que procede de la palabra italiana graffito (incisión sobre una superficie); se trataba de «firmar» la calle como forma de pertenencia. Posteriormente, esta tendencia, influida por el academicismo en el arte, derivaría en el postgraffiti, donde los artistas comienzan a crear una identidad propia mediante el grafismo, los materiales, y otras técnicas, como por ejemplo, el uso de stencil, y donde la temática gira entorno a la crítica social (Abarca, 2010).

En la década de los noventa se incorporan elementos artísticos mediante una relación armónica con el entramado urbano, identificándoselo con el anglicismo Street Art; mientras que el graffiti de la década de los setenta se conocerá en la escena urbana actual como wild graffiti. Según Abarca (2016), este último se moverá dentro del ámbito de la ilegalidad y la espontaneidad; mientras que el muralismo será identificado como una de las muchas formas del arte urbano, que nace de manera razonada y legal. 


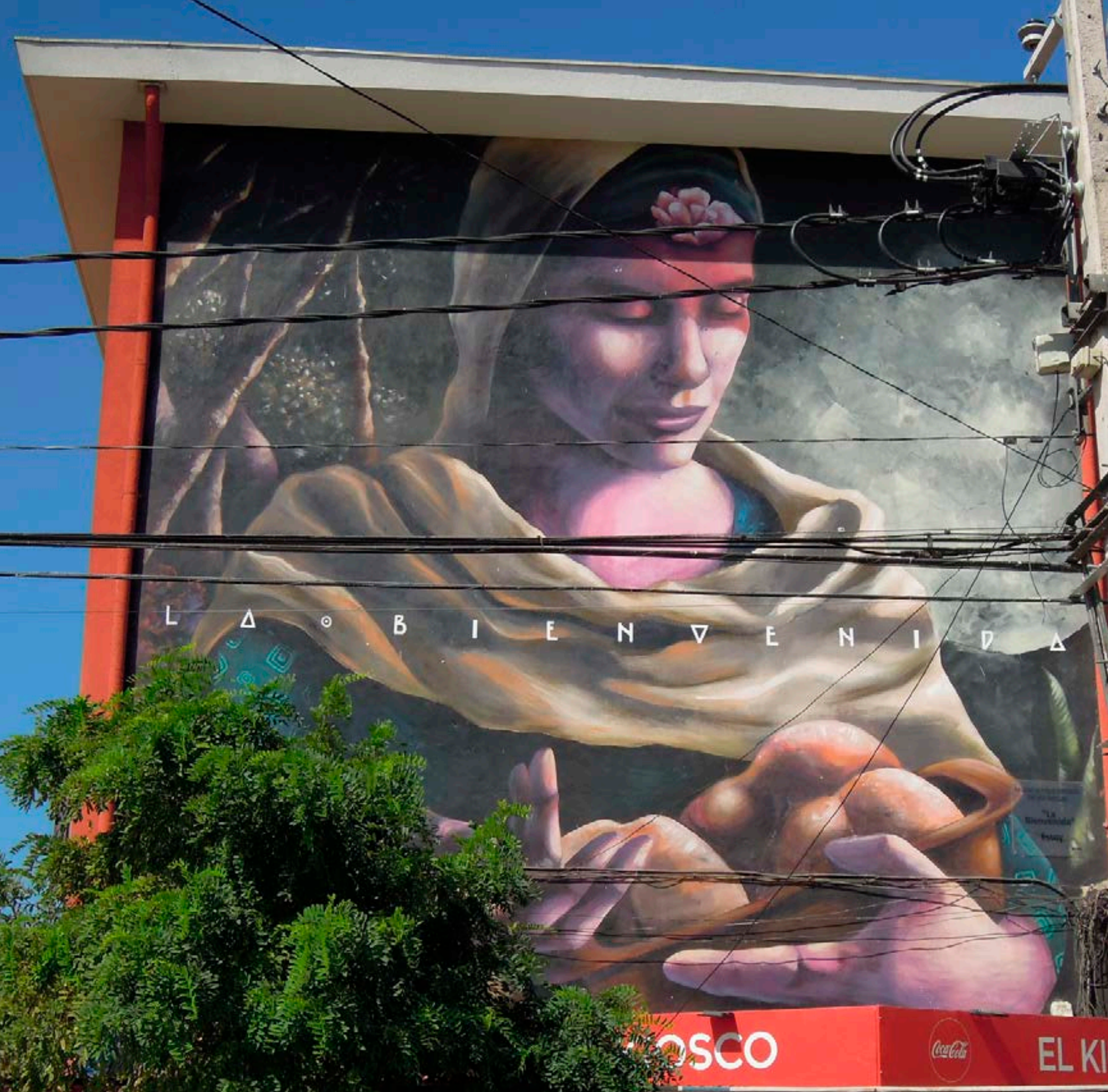

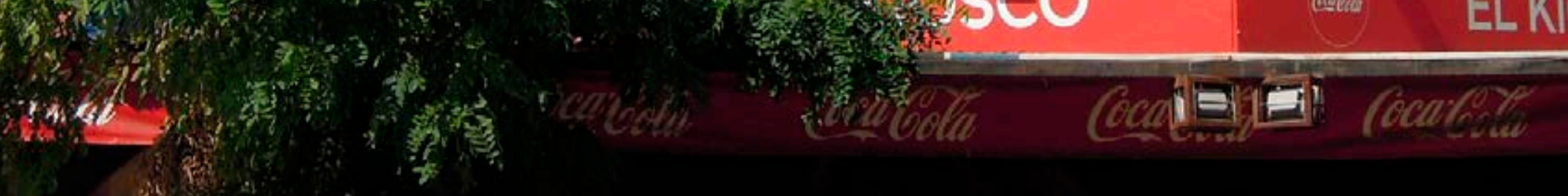


2.5. La Brigada Ramona Parra y la pintura mural chilena

El arte mural en Chile está estrechamente ligado al acontecer político de finales de 1970 . Si bien sus orígenes son imprecisos, se sitúa el nacimiento de la Brigada Ramona Parra (en adelante BRP) en 1969, como una facción propagandística muy cercana a las Juventudes Comunistas chilenas, y compuesta por artistas plásticos, generalmente autodidactas, entre los que destaca Alejandro «Mono» González (Memoria Chilena, s.f.).

Los murales de la BRP, destacan por sus vívidos colores, y el grueso delineado en negro de sus siluetas. La temática brigadista versa sobre el ideario colectivo del modo de generar un diálogo con el espectador. Estas pinturas se realizaban de manera combinada por fondeadores, trazadores y rellenadores; lo que permitía que el trabajo se realizara a gran velocidad (Grandón Leal, 2010).

\section{Metodología}

El paisaje musealizado consiste en el resultado de un proceso de musealización, donde el paisaje adquiere ciertas características de los museos tradicionales. Esta transformación se enmarca dentro de un contexto fenomenológico, ya que deben cumplirse ciertas condiciones que la propicien.

La fenomenología, corriente filosófica impulsada por Husserl durante el siglo xx, apunta a que los objetos ideales, o ideas, existen puesto que son válidas, y que el sujeto debe limitarse a describirlas evitando juicios valorativos (Husserl, 2012). Esta experiencia subjetiva es sublimada por el teórico y discípulo de Husserl, Merleau-Ponty, quien propone que estos objetos ideales son parte de la experiencia humana, y que el foco de interés está principalmente en describir esa realidad desde una perspectiva subjetiva en donde el hombre es a la vez sujeto y objeto (Merleau-Ponty y Cabanes, 1975). De este modo, la experiencia del investigador se tornará fundamental en el análisis subjetivo de un caso de estudio.

El ICOM (2017) destaca ciertas particularidades que resultan fundamentales para la musealización, y que distinguirían este tipo de otros similares pero que no han alcanzado este estatus. Mediante el análisis cualitativo del contenido sobre la definición del ICOM, anteriormente mencionada, se desprenden al menos tres puntos relevantes que permiten interpretar el Museo a Cielo Abierto en San Miguel como paisaje musealizado. Estos son:

- Poseer un patrimonio material e inmaterial, elemento que puede resumirse como una de las principales características de un museo.

- Brindar un servicio a la sociedad, punto que se relaciona directamente con el tratamiento que la institución ejecuta sobre el patrimonio que custodia y que, a través de la mediación, educación y difusión, resulta beneficioso para la comunidad.

- Establecer políticas de conservación y restauración, que se vinculen con la preservación del patrimonio, hecho que se dificulta particularmente en los paisajes musealizados por contar con piezas creadas para exponerse en el exterior.

La definición de museo del ICOM de 2017 genera múltiples perspectivas que atañen a la labor museística. No obstante, los tres puntos mencionados funcionan como síntesis de las principales características que se reflejan en los paisajes musealizados.

\section{Resultados}

\subsection{El Museo a Cielo Abierto en San Miguel}

La comuna de San Miguel se ubica en el centro sur de la ciudad de Santiago de Chile, colindando con las comunas de Santiago Centro, San Joaquín, San Ramón, La Cisterna y Pedro 


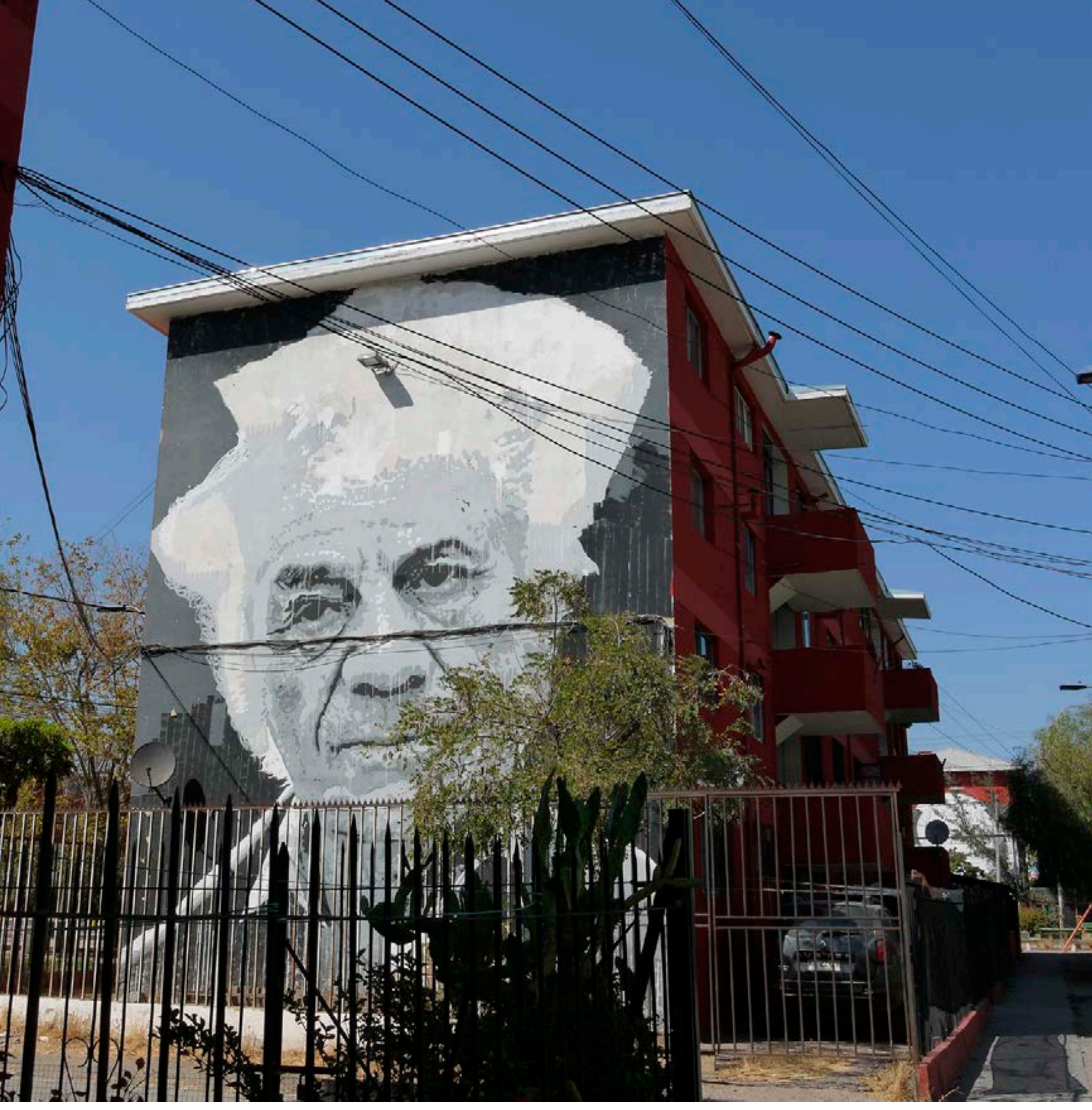

Mural nº 44, Yo soy el individuo. Artistas: Colectivo B (Lee, Tono y Giuliana), 2015. Fuente: G. Derosas 
Aguirre Cerda. En Chile se utiliza la palabra «comuna» para designar una división administrativa dentro de la ciudad, siendo el equivalente a «distrito» en España.

El museo se encuentra dentro del perímetro formado por la Avenida Departamental, la calle Gauss, calle Carlos Edwards y Pasaje O, y por la Panamericana Sur (Centro Cultural Mixart, s.f.). Su superficie total es de 950 hectáreas, de las cuales menos de $5000 \mathrm{~m}^{2}$ corresponden a áreas verdes (Reyes Päcke y Figueroa Aldunce, 2010).

La historia de la comuna de San Miguel se remonta a la época colonial; sin embargo, no fue hasta 1900 cuando este sector, mayoritariamente rural, comenzó a ser masivamente poblado, llegando a tener alrededor de siete mil habitantes (Ilustre Municipalidad de San Miguel, s.f.). Durante el siglo XIX, el precio de la vivienda en el área céntrica de Santiago aumentó excesivamente, lo que propició la ocupación de la zona periférica a esta (De Ramón, 1990). Hacia 1960, la Población Miguel Munizaga Mossino, primer nombre que denominó a la actual comuna de San Miguel, fue paulatinamente habitada y urbanizada por particulares, agrupaciones gremiales, trabajadores y programas de vivienda social (Reyes Päcke y Figueroa Aldunce, 2010). Sin embargo, este crecimiento se ralentizó en la década comprendida entre 1982 y 1992 (De Mattos, 2004).

Un año antes del Bicentenario de Chile, que se celebraría en el 2010, los vecinos, padres de familia y concuñados, Roberto Hernández Bravo y Daniel Villarroel Fuentes, proponen aprovechar las medianeras, o muros ciegos, de los blocks de departamentos situados en la vereda norte de la Avenida Departamental a la altura del 1500 (entre las calles Gauss y la Panamericana Sur), para reactivar la comunidad mediante el arte (Centro Cultural Mixart, s.f.).

Para facilitar el éxito del proyecto, se crea el Centro Cultural Mixart; y, en abril de 2010, obtienen el apoyo de la organización comunitaria NODO. El reconocido artista chileno Alejandro «Mono» González, anteriormente mencionado como uno de los fundadores de la BRP, es asignado como director de arte, quien aporta generosamente y de forma gratuita dos murales que servirían como guía para los futuros artistas que participarían en esta propuesta.

El espacio está gestionado por Mixart, y el propio «Mono» González en su calidad de director, quienes se ocupan de las labores administrativas, las cuales se centran, principalmente por motivos de recursos económicos, en la realización de nuevos murales y la restauración de los antiguos. Así mismo, las visitas guiadas se centran principalmente en grupos escolares y privados, previa una pequeña aportación. La realización de talleres depende económicamente de la postulación a fondos públicos, lo que dificulta la práctica periódica de estos.

Los más de cuarenta murales que componen el Museo a Cielo Abierto en San Miguel, tienen dimensiones aproximadas de 85 $\mathrm{m}^{2}$ cada uno; $\mathrm{y}$, según los datos volcados en la propia web del museo, para enero de 2019, estos ocupaban un total de $6000 \mathrm{~m}^{2}$ del barrio donde están localizados.

\subsection{Poseer un patrimonio material e inmaterial}

Al igual que ocurre con otras iniciativas similares, como el Museo di Urban Art di Roma (M.U.Ro) (Italia), ubicado en el barrio de Quadraro, o la Galería de Arte Urbano (GAU) en distintas áreas de la ciudad de Lisboa (Portugal), el Museo a Cielo Abierto en San Miguel, se alza en un área periférica. Esto significa que es un museo alejado del circuito turístico tradicional. No obstante, el complemento de un nuevo patrimonio le otorga un atractivo cultural y turístico a una zona que anteriormente carecía de él, convirtiéndose este en un elemento distintivo y característico. 


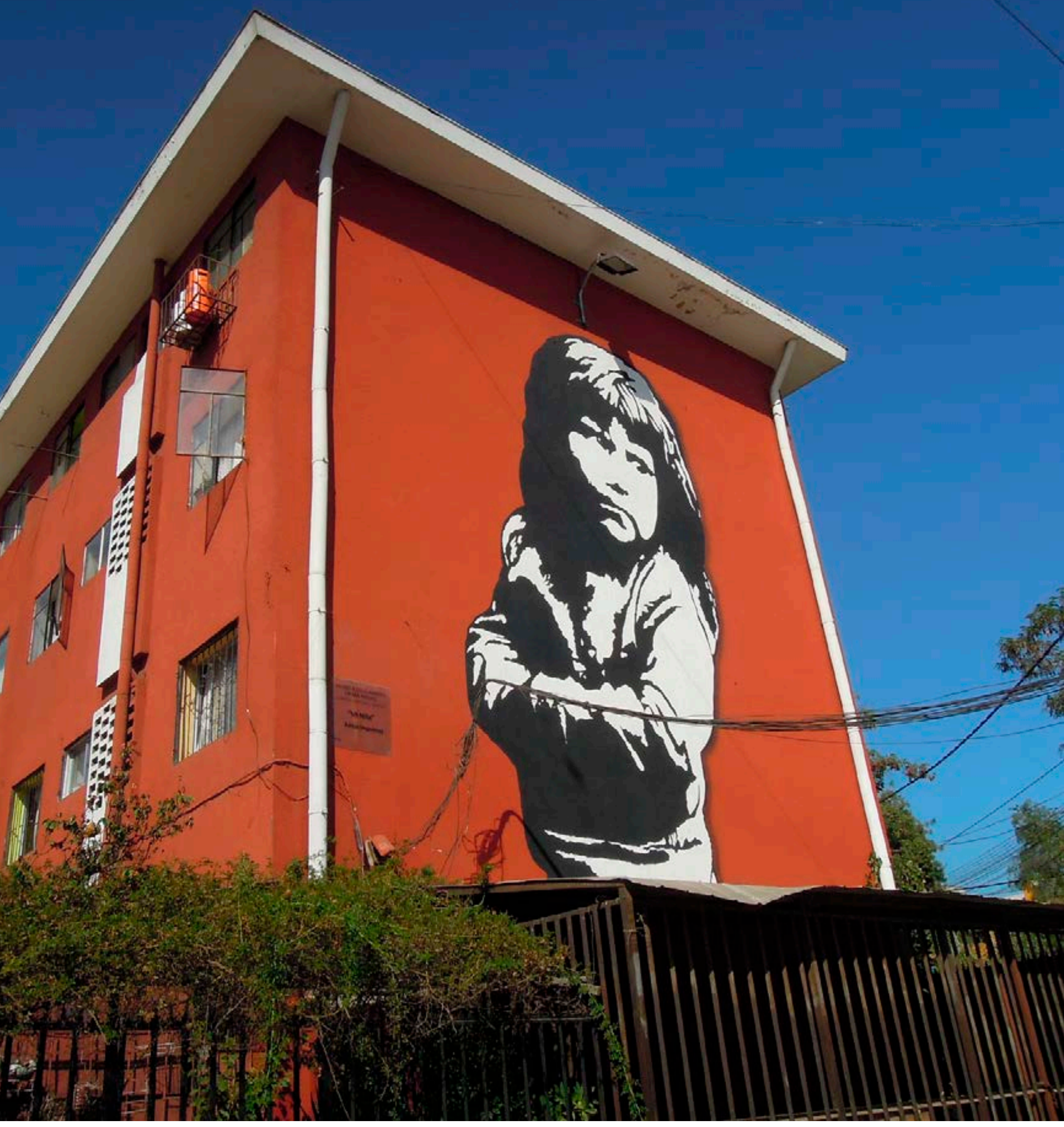

Mural no 39, Mi niña. Artista: Adrián, 2014 
Este tipo de proyectos, como MIAU y el $\mathrm{Mu}$ seo a Cielo Abierto en San Miguel, surgen a partir de la iniciativa vecinal frente a una sensación de vulnerabilidad. Ante dicha situación, los habitantes se organizan para preservar el espacio a través de elementos que contribuyan a su patrimonalización. De este modo, los paisajes urbanos musealizados constituirían otra forma de museo comunitario, ya que nacen de procesos participativos de la comunidad que los alberga (Abarca-Álvarez y Campos-Sánchez, 2013).

El MIAU nace como respuesta social ante la inminente creación de un vertedero tóxico (Derosas Contreras, 2017). Esta respuesta manifiesta una intención inicial de «restauración» urbana, más que artística. Mientras que, en el Museo a Cielo Abierto en San Miguel, la voluntad de «limpiar los muros» se relaciona con el objetivo de reactivar la comuna a través de la decoración de sus medianeras; resultando en la transformación museística del espacio urbano.

La diferencia existente entre museos a cielo abierto «tradicionales» y los paisajes musealizados radica en los «nuevos» elementos patrimoniales que se complementan de manera orgánica en el paisaje. En el caso del $\mathrm{Mu}$ seo a Cielo Abierto en San Miguel, este busca resaltar los elementos comunitarios mediante la ejecución de murales que destaquen valores y características propias de la cultura chilena.

El relato nacional del Museo a Cielo Abierto busca educar mediante el arte, resaltando ciertos valores que caracterizan a Chile. Sin embargo, conviene señalar que son los propios vecinos de San Miguel quienes deciden qué obras se realizarán en los muros ciegos de sus viviendas. Para ello, los residentes de la comuna son previamente consultados para la aprobación de cada una de las pinturas murales. Esto genera un dialogo con las piezas que componen al museo (Rodríguez-Plaza,
2017), las cuales quedan integradas dentro del entramado urbano. Al mismo tiempo, esto refleja que son los vecinos de la comuna de San Miguel quienes escriben el discurso museográfico.

En esta pieza del artista Estoy, se revela como el arte queda integrado de forma orgánica con el entramado urbano de la comuna de San Miguel.

Los temas se enlazan con cuestiones autóctonas que van desde grandes poetas como $\mathrm{Pa}$ blo Neruda, antipoetas como Nicanor Parra, hasta mitología chilota.

\subsection{Brindar un servicio a la sociedad}

Diferentes estudios concuerdan sobre el valor del museo como institución al servicio de la sociedad, pues son herramientas que deben contribuir a la construcción de la memoria social a través de la educación (Do Nascimento Junior, 2008; Garde López y Varela Agüí, 2009; Álvarez Domínguez, 2009). Esto significa que los museos deben generar los medios para que la sociedad pueda disponer de ellos. Por tanto, la mayor contribución social del museo radicará en sus actuaciones educativas.

$\mathrm{Al}$ igual que en los museos tradicionales, en los museos al aire libre, debe existir un ejercicio de mediación entre la obra expuesta y el visitante. Si se promueven estas funciones divulgativas y educativas contribuirán a acortar la distancia entre público y paisaje musealizado. En el Museo a Cielo Abierto en San Miguel esto se resuelve, en un primer momento, mediante la disposición de cartelas informativas que funcionan igual que en los museos tradicionales. La información se complementa a través de la página web del museo, que enriquece la visita de los particulares espontáneos.

Las acciones educativas formales del museo están a cargo del Centro Cultural Mixart, y dependen en su mayoría de fondos públicos y del aporte municipal. Su actividad está centrada 
en visitas guiadas a colegios y grupos particulares concertados; además se realizan talleres que tratan el muralismo, el mosaico y el arte urbano, temas sobre los que se fundamenta el museo.

\subsection{Políticas de conservación y restauración}

En cuanto a la conservación de las piezas, los museos al aire libre poseen la dificultad adicional de que las obras están expuestas constantemente a las inclemencias meteorológicas, y en ocasiones, incluso al vandalismo. En la actualidad, la expansión del concepto patrimonio alcanza a las políticas de preservación del mismo en otros contextos, como el urbano (Layano, 2007).

Entre 2010 y 2013, los primeros murales realizados con látex se han deteriorado por las condiciones climáticas; por tanto, la pintura fue reemplazada por esmaltes al agua, mucho más resistentes. La disposición sobre restaurar o remplazar los murales, cae en manos de los vecinos, quienes previa consulta, eligen qué hacer con las piezas. Posteriormente, se procede a contactar a los artistas originales de cada mural. Según las estadísticas de Mixart, en los dos últimos años, ocho de cada diez murales se han reemplazado (Centro Cultural Mixart en 2019).

\section{Conclusiones}

La musealización del paisaje urbano es el resultado de un proceso de profunda transformación artística. El espacio habitado se mezcla con un patrimonio cultural que se relaciona estrechamente con el contexto. Esto supone un cambio en la percepción del paisaje, el cual adquiere características de museo gracias a la creación de un nuevo patrimonio, lo que significa la ejecución de una serie de acciones educativas, divulgativas y de conservación.
El Museo a Cielo Abierto en San Miguel es un paisaje musealizado con elementos de museo comunitario. Esta experiencia nace de la propia comunidad, que incorpora a la vez elementos patrimoniales materiales (reflejados en los murales como piezas artísticas) e inmateriales (representados en las temáticas inmanentes en las pinturas). El resultado es un museo que posee obras cargadas de un discurso museístico coherente que relata parte de la cultura chilena, bajo la apreciación que los vecinos de San Miguel tienen de su país.

Por otra parte, la dedicación de los habitantes de la comuna al envolverse personalmente en las decisiones trascendentales que atañen al museo, tanto en la elección de los murales, la disposición de las piezas, y la conservación de las mismas, habla de la imagen de barrio que buscan proyectar. El patrimonio, creado por y para los vecinos de San Miguel, da cuenta de que la estrecha relación que existe entre estos y el paisaje habitado, supone no solo el embellecimiento del espacio urbano; sino también la musealización del barrio como conjunto artístico.

Las actuaciones educativas y de difusión del Museo a Cielo Abierto integran obra y paisaje al mediar entre estos y el público. La presencia de cartelas que informan sobre el artista, nombre de la pieza y año en que fue elaborada, evidencian la intención de tratar las obras como se haría en un museo tradicional. Esto no sucede en todos los autodenominados museos; como Beco da Codorna, espacio que carece de referencias a las piezas o los artistas, más allá de las firmas dispuestas en alguna esquina de los murales.

Al igual que otros museos similares, las políticas de conservación, restauración y reemplazo de obras están sujetas a la importancia de las piezas sobre el imaginario colectivo. En el Museo a Cielo Abierto de San Miguel, los vecinos eligen las obras y deciden la permanencia o sustitución de unas por otras; y como 
ocurre con el MIAU de Fanzara, algunas piezas se vuelven icónicas (Derosas Contreras, 2017). Esas obras son las que adquirirán permanencia, y se restaurarán, idealmente, por los propios artistas que las crearon. Sin embargo, si estas piezas no consiguen alcanzar dicha categoría, se reemplazan por otras; siendo así, museos en constante cambio. En el Museo a Cielo Abierto en San Miguel, la obra artística y el paisaje urbano se complementan de forma armónica originándose un paisaje musealizado.

Agradecimientos: a Mono González, y a Roberto Marcos, de la Fundación Mixart, por la información facilitada. A Eva G. Bullido por la traducción, y a Gabriel Derosas por las fotografías.

\section{REFERENCIAS / BibLIOGRAFÍA}

Abarca-Álvarez, Francisco Javier y CAmposSÁnchez, Francisco Sergio (2013) «Urbanismos sin lugar: paisajes participados». Bitácora Urbano Territorial, 22 (1), 53-60.

AbARCA, Javier (2010) «El papel de los medios en el desarrollo del arte urbano». AACADigital: Revista de la Asociación Aragonesa de Críticos de Arte, 12, 2.

AbARCA, Javier (2016) «From street art to murals: what have we lost?». Street Art \& Urban Creativity Scientific Journal, 2 (2), 60-67.

Álvarez Domínguez, Pablo (2009) «Espacios educativos y museos de pedagogía, enseñanza y educación». Cuestiones pedagógicas, 19, 191-206.

Aproveite A Cidade (2017) «Aproveite a cidade». [En línea]. Available at: http://aproveiteacidade. com/cidade/goiania/o-que-os-grafites-do-becoda-codorna-mostram-sobre-sua-percepcao-degoiania/ [Fecha de consulta: 12-07-2019].
AzócAr, Miguel Ángel (2007) A treinta y cinco años de la Mesa Redonda de Santiago de Chile. s.l., s.n., p. IX Seminario sobre Patrimonio Cultural Museos en Obra.

Carbonell, Eduard (2005) «Reflexiones en torno a los museos, hoy». Museos.es, Revista de la Subdirección General de Museos Estatales, 1, 12-21.

Centro Cultural Mixart (s.f.) «Museo a Cielo Abierto en San Miguel». [En línea]. Available at: https://www.museoacieloabiertoensanmiguel. cl/wp-content/uploads/2017/03/poblacion-sanmiguel.pdf [Último acceso: 9 Agosto 2019].

Centro Cultural Mixart (s.f.) «Museo a Cielo Abierto en San Miguel». [En línea]. Available at: https://www.museoacieloabiertoensanmiguel.cl/ wp-content/uploads/2017/03/historia-de-proyecto. pdf [Último acceso: 9 Agosto 2019].

Centro Cultural Mixart (s.f.) «Museo a Cielo Abierto en San Miguel». [En línea]. Available at: https://www.museoacieloabiertoensanmiguel.cl/ wp-content/uploads/2017/03/museo-intro.pdf [Último acceso: 9 Agosto 2019].

Contés, Fernanda (2016) «Museo a Cielo Abierto en San Miguel y la construcción estética de la memoria». En: La Historia del Arte en diálogo con otras disciplinas. Valparaiso: Museo Histórico Nacional.

Crus-Ramírez, Alfredo (1985) «El Heimatmuseum: un precursor pervertido». Museum International, 3 (4), 242-244.

Danysz, Magda (2016) Antología del Arte Urbano. Del graffiti al arte contextual. Barcelona: Promopress.

De CARli, Giorgina (2004) «Vigencia de la Nueva Museología en América Latina: conceptos y modelos». Revista Abra, 24 (33), 55-75.

De Mattos, Carlos (2004) «Santiago de Chile: Metamorfosis bajo un nuevo impulso de modernización capitalista». En: Santiago en la globalización: ¿una nueva ciudad? Santiago: Ediciones Sur, Libros EURE, 17-46.

De RAmón, Armando (1990) «La población informal. Poblamiento de la periferia de Santiago de Chile. 1920-1970». Revista EURE, XVII (50), 5-17.

Derosas Contreras, Daniela (2017) «Museo Inacabado de Arte Urbano (MIAU): Musealización del paisaje urbano». Didácticas Específicas, 17, 99108.

Do Nascimento Junior, José (2008) «Los museos como agentes de cambio social y desarrollo». Museos.es: Revista de la Subdirección General de Museos Estatales, 4, 16-27.

Fernández DE PAZ, Esther (1997) «El estudio de la cultura en los Museos Etnográficos». PH: Boletín del 
Instituto Andaluz del Patrimonio Histórico, 5 (18), 109-118.

García de la Vega, Alfonso y Derosas Contreras, Daniela (2017) «Análisis del paisaje en los museos. La perspectiva sobre el paisaje musealizado». Educación y futuro: revista de investigación aplicada y experiencias educativas, 36, 19-37.

Garde López, Virginia. y VArela Agüí, Enrique (2009) " ¿Al servicio de la sociedad y de su desarrollo? El Laboratorio Permanente de Público de Museos: una herramienta de gestión». Museos.es: Revista de la Subdirección General de Museos Estatales, 5, 208221.

Grandón LeAL, Romina (2010) «Brigadas Ramona Parra: muralismo político y debate cultural en la Unidad Popular». Tesis de grado, Universidad Alberto Hurtado. [En línea]. Available at: http:// repositorio.uahurtado.cl/handle/11242/6283 [Último acceso: 13 Noviembre 2019].

Husserl, Edmund (2012) La idea de la fenomenología. Barcelona: Herder.

ICOM (2017) «Definición de Museo». [En línea]. Available at: https://icom.museum/es/news/thechallenge-of-revising-the-museum-definition/ [Último acceso: 19 Agosto 2019].

ICOM (2017) «Código de deontología». [En línea]. Available at: https://icom.museum/es/actividades/ normas-y-directrices/codigo-de-deontologia/ [Último acceso: 19 Agosto 2019].

Ilustre Municipalidad DE SAN Miguel (s.f.) «Ilustre Municipalidad de San Miguel». [En línea]. Available at: http://web.sanmiguel.cl/historia-de-la-comuna/. [Último acceso: 19 Agosto 2019].

Instituto Brasileiro de Museus (2014) Museus e turismo. Brasilia: Instituto Brasileiro de Museus.

LAyuno, María Ángeles (2007) «El museo más allá de sus límites. Procesos de musealización en el marco urbano y territorial». Oppidum, 3, 133-164.

Lopes, María Margaret y Murriello, Sandra Elena (2005) «El movimiento de los museos en Latinoamérica a fines del siglo XIX: el caso del museo de la Plata». Asclepio, 57 (2), 203-222.

Lorente, PedroJesús (2009) «¿Quéesy cómo evoluciona un barrio artístico? Modelos internacionales en los procesos de regeneración urbana impulsados por las artes». En: Arte en el espacio público: barrios artísticos y revitalización urbana. Zaragoza: Prensas Universitarias de Zaragoza.

memoria Chilena, Biblioteca Nacional de Chile (s.f.) «Pintura Social en Chile. Las Brigadas Ramona Parra». [En línea]. Avaiable at: http://www. memoriachilena.gob.cl/602/w3-article-100581. html [Último acceso: 13 Noviembre 2019].
Merleau-Ponty, Maurice y Cabanes, Juan (1975) Fenomenología de la percepción. Barcelona: Península.

MIAU Fanzara (s.f.) «M.I.A.U. museo inacabado de arte urbano». [En línea]. Available at: http://miau32. wixsite.com/miaufanzara-2016 [Fecha de consulta: 2-07-2019].

Raquejo, Tonia (2008) Land Art. San Sebastián: Nerea.

Reyes PÄcke, Sonia y FigueroA Aldunce, Isabel Margarita (2010) «Distribución, superficie y accesibilidad de las áreas verdes en Santiago de Chile». Revista EURE, 36 (109), 89-110.

Rodrigues, Livia Nunes Borges (2015) Caligrafia marginal: pichação, performance e patrimônio. Goiânia, s.n.

Rodríguez-Plaza, Patricio (2017) «El Museo a Cielo Abierto en San Miguel: Apuntes para un trabajo poblacional». AUS Arquitectura/Urbanismo/ Sustentabilidad, 22, 12-18.

Ruhrberg, Karl, et al (2012) Lart au XXe siècle. Taschen.

TomÀs, Agustí Andreu (2012) «Los museos de etnología en Europa: entre la redefinición y la transformación». Ilha Revista de Antropología, 14 (1), 83-114.

VILAs, Felipe Arias (1999) «Sitios musealizados y museos de sitio: Notas sobre dos modos de utilización del patrimonio arqueológico». Museo: Revista de la Asociación Profesional de Museólogos de España, 4, 39-57.

Recibido el 30 del 9 de 2019

Aceptado el 18 del 11 de 2019 BIBLID [2530-1330 (2019): 98-111] 